\title{
Study on the Performance of HDP Asphalt Rubber Mixture
}

\author{
Gao-yanzhi ,Xu-zhoufeng \\ (Sichuan College of Architectural Technology, traffic and municipal engineering, DeYang \\ Sichuan ,618000)
}

Keywords: HDP; rubber asphalt; asphalt mixture; mix design; road performance

Abstract: HDP rubber asphalt mixture is made of rubber asphalt with a certain amount of HDP additive. The HDP rubber asphalt by Marshall design method with ratio design, of Marshall specimens tested the related technical indicators, to determine the optimum mix amount of HDP, aggregate synthesis of gradation and mixture of optimal asphalt aggregate ratio. Through the indoor experiment, the HDP rubber asphalt mixture material of rutting test, bending test at low temperature and freeze thaw split test, evaluate the mixture road performance and verify the HDP asphalt rubber mixture material with good temperature stability and anti water damage ability.

\section{INTRODUCTION}

HDP rubber asphalt is a kind of composite modified asphalt, which is made of HDP and rubber powder and matrix asphalt. Asphalt rubber is rubber powder and asphalt mixture into a product, as defined by ASTM D-6114 standard is composed of asphalt, waste tire rubber powder and some additives mixture, which rubber content not less than $15 \%$, and in the hot asphalt production of crumb rubber particles bulging melting reaction of modified asphalt cementing materials. HDP (high durability pavement) is a kind of modified agent which is introduced by Japan. A self catalytic reaction was occurred in the reaction of HDP with the rubber asphalt at a certain temperature, and the product has the similar properties with the epoxy resin system. The research shows that ${ }^{[1]}$, the rubber can improve the flexibility of asphalt, the process of rubber modified asphalt is more complex, which is the result of the absorption reaction and rubber powder particles filling effect, and epoxy resin in a great extent to improve the cohesive force, so as to raise the development of HDP rubber asphalt. In order to improve the anti water damage performance of asphalt pavement, high temperature rutting and low temperature cracking resistance, improve the service level, driving comfort and safety, and prolong the service life of asphalt pavement.

In the course of the use of asphalt pavement, the influence of vehicle load and air factor is directly influenced by vehicle load and air factor. In order to provide a stable, comfortable and durable service for the vehicle, the asphalt pavement must be provided with sufficient stability, durability and anti ageing property. The concrete manifestation of these characteristics mainly include high temperature stability, low temperature crack resistance, water stability, anti aging and fatigue properties.

\section{PREPARATION OF HDP RUBBER ASPHALT}

The matrix of asphalt. Taizhou AH-70 asphalt, in accordance with the 《highway engineering asphalt and asphalt mixture test procedures》 (JTJ052-2000) in the relevant provisions of the 
Taizhou AH-70 asphalt, the main technical indicators for testing, the results are shown in table 1 .

Table 1 The test results of main technical specifications forAH- 70 bitumen

\begin{tabular}{|c|c|c|c|c|}
\hline \multicolumn{2}{|c|}{ Test items } & unit & Measured value & Technical \\
\hline \multicolumn{2}{|c|}{ Penetration $\left(25^{\circ} \mathrm{C}, 5 \mathrm{~s}\right.}$, & $0.1 \mathrm{~mm}$ & 78 & $60 \sim 80$ \\
\hline \multicolumn{2}{|c|}{ Ductility $\left(15^{\circ} \mathrm{C}\right)$} & $\mathrm{cm}$ & $>150$ & $\nless 100$ \\
\hline \multicolumn{2}{|c|}{ Softening point (universal } & ${ }^{\circ} \mathrm{C}$ & 49.5 & $\nless 46$ \\
\hline \multicolumn{2}{|c|}{ Density $\left(15^{\circ} \mathrm{C}\right)$} & $\mathrm{g} / \mathrm{cm} 3$ & 1.042 & Measured record \\
\hline \multirow{2}{*}{$\begin{array}{c}\text { Residu } \\
\text { e after } \\
\text { TFOT }\end{array}$} & Quality change & $\%$ & 0.02 & $\ngtr \pm 0.8$ \\
\cline { 2 - 5 } & Penetration ratio & $\%$ & 68.0 & $\nless 61$ \\
\cline { 2 - 5 } & Ductility & $\mathrm{cm}$ & 8.5 & $\nless 6$ \\
\hline
\end{tabular}

The rubber powder.Rubber powder is short for rubber powder. In accordance with the normal temperature of the grinding method will be discarded waste rubber tire processing and grinding into powder. Waste tire rubber powder, the main chemical composition is the natural rubber, synthetic rubber, carbon black, iron oxide, silicon oxide, such as additive components ${ }^{[2]}$. These ingredients can be used as a modifier for asphalt properties. Will grind the waste rubber powder to add to the asphalt, can play to improve the road performance of asphalt mixture, reduce the role of driving noise. At the same time can solve the "black pollution" caused by the social environment and other issues, and our country to speed up the construction of a conservation oriented society, environment friendly society of sustainable development strategy. In accordance with the United States ASTM6144-97 standard ${ }^{[3]}$, the rubber powder content is usually not less than $15 \%$ of the amount of asphalt. In this experiment, the content of rubber powder is $18 \%$, and the rubber powder is added in wet process.

The HDP additive. The HDP additive made by Japan is composed of main agent and curing agent, and the technology index of HDP additive is listed in Table 2. Where HDP is the proportion of 61:39 by the main agent and the hardening agent.

Table 2 Technology index of HDP additive and its main agent and curing agent

\begin{tabular}{|c|c|c|c|c|}
\hline Technical index & The main agent & Hardening agent & HDP & Test method \\
\hline Color & Colorless & Canary yellow & Canary yellow & Observation method \\
\hline Viscosity $[\mathrm{mPa} \cdot \mathrm{s}]$ & 12600 & 43 & 9870 & T0625 \\
\hline Density $[\mathrm{g} \cdot \mathrm{cm}-3]$ & 1.18 & 0.84 & - & JIS K2421 \\
\hline
\end{tabular}

\section{The Mix proportion design of HDP rubber asphalt mixture}

The HDP rubber asphalt.HDP rubber asphalt is a kind of composite modified asphalt, which is made of HDP and rubber powder and matrix asphalt. By analyzing the mechanism of HDP rubber modified asphalt, it was found that the HDP main agent and the hardening agent mixed with ${ }^{[4]}$, HDP and rubber powder, which has the effect of HDP, and has the characteristics of high temperature stability and fatigue resistance. The technical indexes of the HDP rubber asphalt used in the mix are shown in Table 3 . The content of rubber powder was $18 \%$ and the content of HDP was $20 \%$. 
Table 3 HDP rubber as phalt performance specifications

\begin{tabular}{ccccccc}
\hline $\begin{array}{c}\text { Technical } \\
\text { index }\end{array}$ & $\begin{array}{c}\text { Penetration } \\
\left(25^{\circ} \mathrm{C}\right) \\
{[0.1 \mathrm{~mm}]}\end{array}$ & $\begin{array}{c}\text { Softening } \\
\text { point }\left[{ }^{\circ} \mathrm{C}\right]\end{array}$ & $\begin{array}{c}\text { Ductility } \\
{[\mathrm{cm}]}\end{array}$ & $\begin{array}{c}\text { Density } \\
{[\mathrm{g} / \mathrm{m} 3]}\end{array}$ & $\begin{array}{c}\text { Rubber } \\
\text { powder } \\
\text { Content }[\%]\end{array}$ & $\begin{array}{c}\text { HDP } \\
\text { Content[\%] }\end{array}$ \\
\hline Test result & 43.8 & 69.2 & 7.7 & 1.06 & 18 & 20 \\
\hline
\end{tabular}

The aggregate.In this experiment, we use the aggregate specifications for $9.5-16 \mathrm{~mm}$ (1st material). Gravel, 4.75-9.5 mm (2nd material) gravel rock often Hui, 2.36-4.75mm (3rd material). Gravel, 0$2.36 \mathrm{~mm}$ (4th material). Machine-made sand and limestone, slag limestone filler. The relevant technical indicators of the collection are shown in Table 4.

Table4 The test results of aggregate

\begin{tabular}{|c|c|c|c|}
\hline Name & $\begin{array}{c}\text { Apparent relative } \\
\text { density }\end{array}$ & $\begin{array}{c}\text { Gross volume relative } \\
\text { density }\end{array}$ & $\begin{array}{c}\text { Water absorption } \\
\text { rate[\%] }\end{array}$ \\
\hline 1st $(9.5-16 \mathrm{~mm})$ & 2.902 & 2.869 & 0.36 \\
\hline 2nd $(4.75-9.5 \mathrm{~mm})$ & 2.881 & 2.839 & 0.47 \\
\hline 3rd $(2.36-$ & 2.728 & 2.685 & 0.63 \\
\hline 4th $(0-2.36 \mathrm{~mm})$ & 2.718 & $/$ & $/$ \\
\hline Breeze & 2.703 & $/$ & $/$ \\
\hline
\end{tabular}

determination of synthetic gradationHDP rubber asphalt mixture gradation according to

《highway asphalt pavement construction technology standard F40-2004 JTG》 value, using AC$13 \mathrm{C}$ type $^{[5]}$, the result of the synthesis of the graded table 5 .

Table 5 The design gradation of AC-13C bituminous mixture

\begin{tabular}{|c|c|c|c|c|c|c|c|c|c|c|}
\hline \multirow{2}{*}{ Gradation type } & \multicolumn{7}{|c|}{ The percentage of quality following mesh (square hole sieve, $\mathrm{mm}$ ) [\%] } \\
\cline { 2 - 12 } & 16 & 13.2 & 9.5 & 4.75 & 2.36 & 1.18 & 0.6 & 0.3 & 0.15 & 0.075 \\
\hline AC-13 Upper limit & 100 & 100 & 85 & 68 & 50 & 38 & 28 & 20 & 15 & 8 \\
\hline AC-13 The lower limit & 100 & 90 & 68 & 38 & 24 & 15 & 10 & 7 & 5 & 4 \\
\hline AC-13 Median & 100 & 95 & 76.5 & 53 & 37 & 26.5 & 19 & 13.5 & 10 & 6 \\
\hline Synthetic gradation & 100 & 94 & 74.8 & 43.0 & 25.7 & 21.0 & 15.8 & 11.9 & 9.5 & 5.5 \\
\hline
\end{tabular}

To determine the optimum asphalt aggregate ratio. Determination of HDP rubber asphalt mixture is designed by Marshall method. The mixing temperature of the mixture is $165 \sim 170$, and the mixture is placed at a temperature of 155 degrees centigrade for a period of time in the oven, and the 75 time is adopted by double side impact. Determination of HDP asphalt rubber mixture material test piece Marshall stability, flow value, bulk density, porosity, voids in mineral aggregate, asphalt saturation, and ultimately determine the HDP asphalt rubber mixture material optimum asphalt aggregate ratio of $5.1 \%$.

\section{HDP rubber asphalt mixture performance test}

The high tempe rature stability.High temperature stability of asphalt pavement is the ability to resist permanent deformation of asphalt mixture under load. The high temperature stability of asphalt pavement is mainly reflected in the adverse upheaval, bleeding, rut. At present, the method for evaluating the high temperature stability of high grade asphalt pavement is commonly used in China. The principle is to observe and detect the response of the test block or pavement results by 
using the wheel on the surface of the plate and the pavement structure.

Test methods are as follows: first according to 《highway engineering asphalt and asphalt mixture test procedures in the》(JTG E20-2011) wheel grinding method of forming the specimen, size of $300 \mathrm{~mm} \times 300 \mathrm{~mm} \times 50 \mathrm{~mm}$, wheel pressure of $0.7 \mathrm{MPa}$, test temperature is $60^{\circ} \mathrm{C}$, using ZCZ10 full automatic single and double wheel rut tester test specimen real-time deformation calculated dynamic stability. HDP rubber asphalt mixture high temperature rutting test results see table 6 .

Table6 Results of high te mperature rutting test

\begin{tabular}{cccc}
\hline $\begin{array}{c}\text { Test temperature } \\
{\left[{ }^{\circ} \mathrm{C}\right]}\end{array}$ & $\begin{array}{c}\text { Trial Part } \\
\text { Number }\end{array}$ & $\begin{array}{c}\text { Dynamic } \\
\text { stability[ Time } \\
/ \mathrm{mm}]\end{array}$ & $\begin{array}{c}\text { Average dynamic } \\
\text { stability } \\
{[\text { Time/mm] }}\end{array}$ \\
\hline \multirow{2}{*}{60} & 1 & 4128 & \\
& 2 & 4069 & 4157 \\
& 3 & 4275 & \\
\hline
\end{tabular}

Table 6 test results show that the dynamic stability of HDP rubber asphalt mixture is 4157 times $/ \mathrm{mm}$, which meets the requirements of the code on the stability of modified asphalt mixture should be greater than $3000 / \mathrm{mm}$ requirements, indicating that the high temperature stability has good stability. Referring to the measured value of the dynamic stability of epoxy asphalt mixture and the Japanese standard, the stability of the $2000 \sim 6000 / \mathrm{mm}$ is consistent, which indicates that the HDP rubber asphalt mixture has good anti rut ${ }^{[6]}$.

B.The low temperature anti cracking

Low temperature cracking resistance of asphalt pavement to resist low temperature shrinkage cracking. The low temperature cracking of asphalt pavement is related to the volume shrinkage of the material caused by the decrease of the temperature. When the temperature stress reaches the tensile strength of the material, it is possible to produce cracks.

The low temperature performance of asphalt mixture is more, and the low temperature performance of HDP asphalt mixture is evaluated by low temperature bending test. The low temperature bending test is usually used in the $250 \mathrm{~mm}, 30 \mathrm{~mm}, 50 \mathrm{~mm} / \mathrm{min}, 35 \mathrm{~mm}$, and the span is $200 \mathrm{~mm}$, and the load rate is 10 degrees below zero. According to the test results, the flexural strength, flexural strength, flexural strength and flexural stiffness of the specimens were calculated, and the results were shown in Table 7.

Table 7 Results of high te mperature rutting test

\begin{tabular}{ccccc}
\hline $\begin{array}{c}\text { Test } \\
\text { temperature }\left[{ }^{\circ} \mathrm{C}\right]\end{array}$ & $\begin{array}{c}\text { Trial Part } \\
\text { Number }\end{array}$ & $\begin{array}{c}\text { Flexural tensile } \\
\text { strength[MPa] }\end{array}$ & $\begin{array}{c}\text { Maximum } \\
\text { bending } \\
\text { strain [ } \mu \varepsilon\end{array}$ & $\begin{array}{c}\text { Bending stiffness } \\
\text { modulus [MPa] }\end{array}$ \\
\hline \multirow{2}{*}{10} & 1 & 10.84 & 2956 & 2597 \\
& 2 & 10.63 & 2887 & 2634 \\
\hline Mean value & 3 & 10.38 & 2839 & 2577 \\
\hline
\end{tabular}

From table 7 test results show that the maximum bending strain of HDP rubber mixture is 2894, which is in accordance with the specification of the maximum bending strain of the modified asphalt mixture is not less than 2500, which indicates that the HDP rubber asphalt mixture has good low temperature anti cracking performance.

C.The water stability test

Water damage is a common disease of asphalt pavement, whether it is in frozen areas, or in the 
South rainy regions, it is possible to occur. Freeze thaw splitting tensile strength test of the actual pavement on the impact of the water to focus on strengthening, simulating the moisture permeable asphalt film adsorbed on the interface between asphalt and stone, resulting in the adhesion between asphalt and stone reduced ${ }^{[8]}$. This method can reflect the degree of water damage of asphalt mixture, so as to evaluate the water stability of asphalt mixture.

Table8 Results of freeze thaw split test

\begin{tabular}{ccccc}
\hline \multicolumn{2}{c}{$\begin{array}{c}\text { Without freezing and } \\
\text { thawing cycles }\end{array}$} & $\begin{array}{c}\text { Freezing and thawing } \\
\text { cycles }\end{array}$ & $\begin{array}{c}\text { Freeze thaw } \\
\text { splitting } \\
\text { tensile }\end{array}$ \\
$\begin{array}{ccccc}\text { Splitting } \\
\text { tensile }\end{array}$ & $\begin{array}{c}\text { Mean } \\
\text { value } \\
\text { strength }[\mathrm{MPa}]\end{array}$ & $\begin{array}{c}\text { Splitting } \\
\text { tensile } \\
\text { strength } \\
{[\mathrm{MPa}]}\end{array}$ & $\begin{array}{c}\text { Mean } \\
\text { value } \\
{[\mathrm{MPa}]}\end{array}$ & $\begin{array}{c}\text { strength ratio } \\
{[\%]}\end{array}$ \\
\hline 1.37 & 1.36 & 1.26 & 1.27 & $93 \%$
\end{tabular}

Table 8 test results show that the water stability of HDP rubber asphalt mixture can be determined by freeze-thaw splitting tensile strength test. Because the HDP rubber asphalt mortar in rubber powder swelling needs a larger gap. The material has enough space for HDP asphalt rubber mortar lateral flow can effectively improve the asphalt and aggregate bond strength, improve the water stability of mixture.

\section{Conclusions}

In HDP rubber asphalt system, HDP main agent combined with sclerotherapy occurred autocatalytic reaction and HDP central oxygen radicals and rubber powder thiol groups react, generating a polymer rubber three-dimensional network structure, both HDP epoxy and rubber both common advantages ${ }^{[9]}$. The pavement performance test of HDP asphalt mixture was carried out by means of high temperature stability, low temperature cracking resistance and water stability test. The results show that the HDP asphalt mixture has good temperature stability and anti water damage ability, and can improve the durability of pavement, so as to improve the service life of asphalt pavement.

\section{REFERENCE}

[1] Shen J, Amirkhanian S. The influence of crumb robber modifier (CRM) microstructures on the high temperature properties of CRM binders [J]. The International Journal of Pavement Engineering, 2005, 6(4):265-271.

[2] Lv wenmin ,Sun daquan. Asphalt mixture design manual: First edition [M].BeiJJing: People's Communications Press,2007.

[3] ASTM D6144-97 Standard Specification for Asphalt Rubber Binder [Z], 1998.

[4] Feng wenxin,Ji guoqing,Kong xianming. In recent years, research on crumb rubber modified asphalt [J]. Petroleum pitch,2008,22(1):6-11.

[5] Shen jinan. Pavement performance of asphalt and asphalt mixture [M].Beijing: People's Communications Press,2001.

[6] Huang wenyuan,Zhang yinxi. Performance characteristics and index system of rubber asphalt for road pavement [J]. Central South Highway Engineering.2007, 32(1):111-114. 
[7] Xiezhen. Design and performance study of high durability asphalt pavement [D]. Chongqing: Chongqing Jiaotong University, 2013.

[8] Liu guiqiu,Shi chuxian,Liu yibiao. Chongqing Jiaotong University [J]. Journal of Hunan University (Natural Science Edition)2008,35(4):29-32.

[9] Gao yanzhi. Pavement Performance of HDP Rubber Asphalt and Mixture [J]. Highway Engineering,2015,40(3):218-222 